Military Technical College Kobry El-Kobbah, Cairo, Egypt.

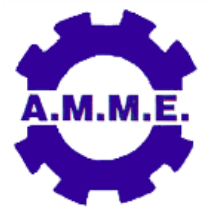

$17^{\text {th }}$ International Conference on Applied Mechanics and Mechanical Engineering.

\title{
IMPACT OF PRECIPITATION IN QUENCH INDUCED STRESSES IN LARGE INDUSTRIAL ALUMINUM PIECES
}

\author{
N. Chobaut ${ }^{1}$, D. Carron ${ }^{2}$, P. Schloth ${ }^{1,3}$ and J.-M. Drezet ${ }^{1,{ }^{*}}$
}

\begin{abstract}
In the processing of heat treatable aluminum alloys, quenching should be fast in order to limit precipitation and to obtain a non-equilibrium solid solution. However high thermal gradients through the thickness of thick components cause nonhomogeneous plastic strain resulting in residual stresses after quenching. Two approaches are presented to predict the as-quenched residual stress distribution in large $2 x x x$ forgings and thick $7 \times x x$ aluminum alloy plates. The first approach consists in characterizing the precipitation that occurs during quenching, e.g. using in situ small angle X-ray scattering, and modelling its impact on the yield strength and thus on the internal stress generation. The second approach is based on a thermomechanical model whose parameters are identified using a limited number of tensile tests achieved after representative interrupted cooling paths in a Gleeble machine. As quenched stresses measured using the neutron diffraction technique are compared with the modelling results and each approach is assessed.
\end{abstract}

1 Swiss Federal Institute of Technology in Lausanne, LSMX, station 12, CH-1015 Lausanne, Switzerland

2 University of Southern Brittany, EA 4250, LIMATB, F-56100 Lorient, France.

3 Swiss Federal Institute of Technology in Lausanne, NXMM, station 12, CH-1015 Lausanne, Switzerland.

* Corresponding author: jean-marie.drezet@epfl.ch. 